\title{
Evolution of a High-Risk Cancer Registry: past, present and future
}

\author{
Michelle S Lewandowski, Thomas M Day, Joslin Christensen, Therese MF Tuohy, Wendy Kohlmann, \\ Deborah W Neklason, Randall W Burt \\ From 13th Annual Meeting of the Collaborative Group of the Americas on Inherited Colorectal Cancer \\ Honolulu, Hawaii, USA. 16-17 October 2009
}

\section{Background}

Huntsman Cancer Institute's High-Risk Cancer Clinics at the University of Utah has followed high-risk colon, pancreatic, melanoma and breast cancer patients, under the auspices of independently run and funded registries, for over 15 years. As knowledge of the genetics of highrisk syndromes and cancers has grown, awareness has emerged of the clinical overlap between risks for these conditions, previously viewed as distinct. To address this growing understanding and to assist in the facilitation of broad-based research efforts, we have embarked on a plan to combine these registries into one single global high-risk cancer registry.

\section{Methods}

The previously independent high-risk colon cancer ( 1,100 enrolled; > 1,300 blood and tissue samples) and pancreatic cancer (242 enrolled; > 195 blood samples) registries were merged into a single IRB-approved Hereditary Gastrointestinal Cancer Registry (HGCR). This merging of registries will take advantage of the known clinical and genetic overlap between these two populations. Research records of participants automatically rolled over into the new registry, therefore re-enrollment was not mandatory. The combined registry enrolls individuals and their family members with a personal and/or family history of gastrointestinal cancer (GI) syndromes and conditions, including those of the pancreas, stomach, and colon as well as large kindreds with excess cancers and unknown etiologies.

\footnotetext{
* Correspondence: michelle.lewandowski@hci.utah.edu

Huntsman Cancer Institute, University of Utah, Salt Lake City, Utah 84112,

USA
}

\section{Results}

The combined HGCR currently includes over 1,400 enrolled participants from $\sim 400$ kindreds. Over 1,500 DNA, cell lines, serum and tissue samples are available for affiliated investigator use. Enrolled participants complete personal, family and medical history questionnaires and medical record releases and are asked to provide blood/buccal and surgical tissue samples (where applicable). The HGCR supports multiple types of basic and translational research projects, including two chemoprevention trials for Peutz-Jeghers patients (ongoing) and FAP patients (pending), psychosocial assessments in high-risk cancer families, and multiple molecular studies for mutation identification methods. Family expansion efforts are focused on expanding populations eligible for registry-supported studies. Substantial progress has been made in collecting and abstracting medical records of cancers and GI procedures. More than 800 medical record procedures, including available genetic test results, have been abstracted since the launch of the new registry. Increases in participant referrals to and from genetic counselors, health-care providers and eligible research studies (internally and externally) have been noted and are expected to increase considerably over time.

\section{Conclusions}

Since the successful amalgamation of the colon and pancreatic registries into a single registry, we recognize the necessity and feasibility for combining additional high-risk registries into a large global cancer registry. Future plans include integrating with our high-risk melanoma and breast cancer registries. 


\section{Acknowledgement}

Funded by NCl grants POI-CA073992 (RWB) and ROI-CA04064I (RWB), the Utah Population Database, the Utah Cancer Registry (funded by contract NOI-PC-35141 from the NCI SEER program with additional support from the Utah State Department of Health and the University of Utah) and by the Huntsman Cancer Foundation.

Published: 25 May 2010

doi:10.1186/1897-4287-8-S1-P11

Cite this article as: Lewandowski et al.: Evolution of a High-Risk Cancer Registry: past, present and future. Hereditary Cancer in Clinical Practice 2010 8(Suppl 1):P11.

Submit your next manuscript to BioMed Central and take full advantage of:

- Convenient online submission

- Thorough peer review

- No space constraints or color figure charges

- Immediate publication on acceptance

- Inclusion in PubMed, CAS, Scopus and Google Scholar

- Research which is freely available for redistribution

Submit your manuscript at www.biomedcentral.com/submit 